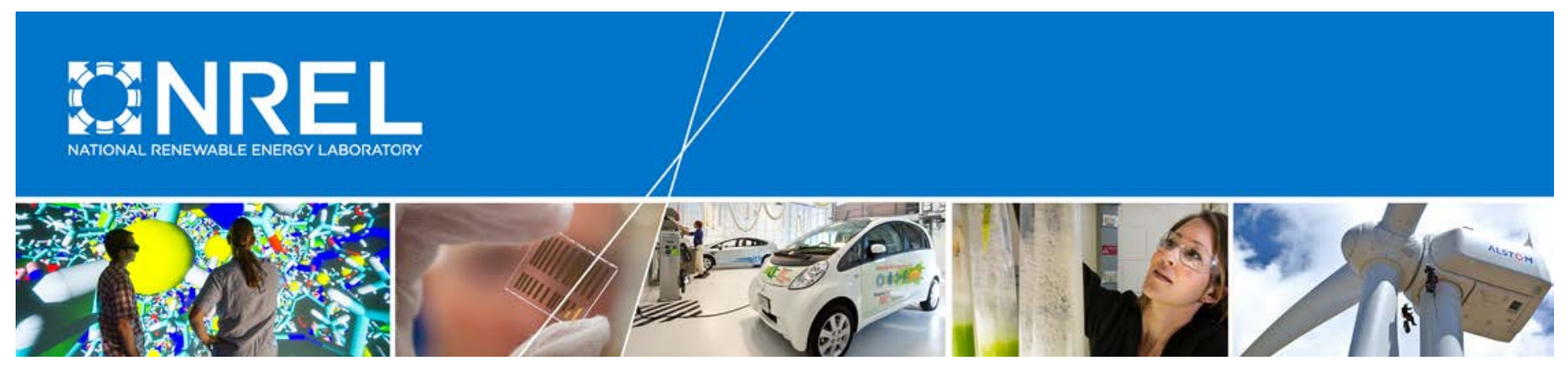

\title{
Renewable Generation Effect on Net Regional Energy Interchange
}

\section{Preprint}

Victor Diakov, Gregory Brinkman, Paul Denholm, Thomas Jenkin, and Robert Margolis National Renewable Energy Laboratory

Presented at the IEEE PES General Meeting Denver, Colorado July 26-30, 2015

NREL is a national laboratory of the U.S. Department of Energy Office of Energy Efficiency \& Renewable Energy Operated by the Alliance for Sustainable Energy, LLC

This report is available at no cost from the National Renewable Energy Laboratory (NREL) at www.nrel.gov/publications.

\section{Conference Paper}

NREL/CP-6A20-63657

July 2015 


\section{NOTICE}

The submitted manuscript has been offered by an employee of the Alliance for Sustainable Energy, LLC (Alliance), a contractor of the US Government under Contract No. DE-AC36-08GO28308. Accordingly, the US Government and Alliance retain a nonexclusive royalty-free license to publish or reproduce the published form of this contribution, or allow others to do so, for US Government purposes.

This report was prepared as an account of work sponsored by an agency of the United States government. Neither the United States government nor any agency thereof, nor any of their employees, makes any warranty, express or implied, or assumes any legal liability or responsibility for the accuracy, completeness, or usefulness of any information, apparatus, product, or process disclosed, or represents that its use would not infringe privately owned rights. Reference herein to any specific commercial product, process, or service by trade name, trademark, manufacturer, or otherwise does not necessarily constitute or imply its endorsement, recommendation, or favoring by the United States government or any agency thereof. The views and opinions of authors expressed herein do not necessarily state or reflect those of the United States government or any agency thereof.

This report is available at no cost from the National Renewable Energy Laboratory (NREL) at www.nrel.gov/publications.

Available electronically at SciTech Connect http:/www.osti.gov/scitech

Available for a processing fee to U.S. Department of Energy and its contractors, in paper, from:

U.S. Department of Energy

Office of Scientific and Technical Information

P.O. Box 62

Oak Ridge, TN 37831-0062

OSTI http://www.osti.gov

Phone: 865.576.8401

Fax: 865.576.5728

Email: reports@osti.gov

Available for sale to the public, in paper, from:

U.S. Department of Commerce

National Technical Information Service

5301 Shawnee Road

Alexandria, VA 22312

NTIS http://www.ntis.gov

Phone: 800.553 .6847 or 703.605 .6000

Fax: 703.605.6900

Email: orders@ntis.gov 


\title{
Renewable Generation Effect on Net Regional Energy Interchange
}

\author{
V. Diakov, G. Brinkman, P. Denholm, T. Jenkin, R. Margolis \\ Strategic Energy Analysis Center \\ National Renewable Energy Laboratory \\ Golden, $\mathrm{CO}$ \\ victor.diakov@nrel.gov
}

\begin{abstract}
Using production-cost model (PLEXOS), we simulate the Western Interchange (WECC) at several levels of the yearly renewable energy (RE) generation, between $13 \%$ and $40 \%$ of the total load for the year. We look at the overall energy exchange between a region and the rest of the system (net interchange, NI), and find it useful to examine separately (i) (time-)variable and (ii) year-average components of the NI. Both contribute to interregional energy exchange, and are affected by wind and $P V$ generation in the system. We find that net load variability (in relatively large portions of $\mathrm{WECC}$ ) is the leading factor affecting the variable component of inter-regional energy exchange, and the effect is quantifiable: higher regional net load correlation with the rest of the WECC lowers net interchange variability. Further, as the power mix significantly varies between WECC regions, effects of 'flexibility import' (regions 'borrow' ramping capability) are also observed.
\end{abstract}

Index Terms - renewable generation, transmission, PV and wind variability, large scale integration.

\section{Notation}

$\operatorname{Corr}\{f, g\}$ Correlation coefficient between two timedependent quantities $f_{t}$ and $g_{t}$

$\operatorname{Mcorr}\{f, g\} \quad$ Mis-correlation between two time-dependent quantities $f_{t}$ and $g_{t}$ defined in equation (1)

$N L^{A}{ }_{t} \quad$ Net load $(\mathrm{GW})$ at hour $t$ for region $A$

$\underline{N L}^{A}{ }_{t} \quad$ Weekly average net load (GW) for region $A$, calculated for the week ending at hour $t-1$

$t \quad$ The (hourly) time index through the year

$T_{t}^{A} \quad$ Net interchange (exports minus imports) between region $A$ and the rest of the system at hour $t(\mathrm{GW})$

$V^{A}{ }_{t} \quad$ Net load variability $N L^{A}{ }_{t}-\underline{N L}_{t}{ }_{t}$ for region $A$

$\sigma_{T} \quad$ Standard deviation $(\mathrm{GW})$ of the net interchange over one year; characterizes the net interchange variability

Abbreviations

AZNMNV Arizona, New Mexico, Nevada

CA No California North

$\begin{array}{cl}\text { CA_So } & \text { California South } \\ \text { NI } & \text { Net interchange } \\ \text { NWPP } & \text { North-West Power Pool } \\ \text { PV } & \text { Photovoltaic power generation } \\ \text { RE } & \text { Renewable energy: PV and/or wind } \\ \text { RMPP } & \text { Rocky Mountains Power Pool } \\ \text { TEPPC } & \text { Transmission Expansion Planning Policy } \\ & \text { Committee (www.wecc.biz/TEPPC) } \\ \text { WECC } & \text { Western Electricity Coordinating Council } \\ \text { WWSIS 2 } & \text { Western Wind and Solar Integration Study } \\ & \text { phase 2 }\end{array}$

I. INTRODUCTION

The need for transmission network expansion in the U.S. is acknowledged [1, 2] with respect to increasing renewable energy fraction in the power mix. Subsequently, detailed studies on projected future grid operation include transmission grid expansion, as a 'one time exercise' [2] or within a framework of electric sector evolution [1]. The focus, as related to transmission, is usually economic and operationally sufficient grid expansion.

In the context of increasing RE presence in the generation mix, compared to transmission expansion, regional energy exchange has drawn less attention and is the focus of our study. As the first step, we examine how large regions within the U.S. part of the Western Interchange $\left(\mathrm{WECC}^{1}\right)$ exchange power with the rest of the system. Following [3], regional power interchange with the rest of the system is referred to as the net interchange (NI). Clearly, a great number of details are omitted when considering the NI for large chunks of the system. Concurrently though, the approach offers a high-level view at energy interchange essentials, relates to large-scale energy exchange as affected by wind and PV, and we expect it to be useful for future more detailed studies.

\footnotetext{
${ }^{1}$ http://www.wecc.biz, accessed on Nov 24, 2014.
}

The work was sponsored by the U.S. DOE EERE 


\section{SYSTEM DESCRIPTION}

WECC TEPPC 2020 database as modified for WWSIS 2 [2] is used to simulate economic dispatch (with production cost model PLEXOS ${ }^{2}$ ), hourly for one year, with transmission limitations imposed as inter-regional 'border interface' constraints, as projected to 2020 .

The generation mix at $27 \%$ wind + solar is shown in Figure 1 with fraction (\%) generation by type given in Table 1. The six large WECC regions ${ }^{3}$ represent a variety of generation mixes. Further, the amount of renewable generation was varied by concurrently scaling up or down wind and PV generators in the system (in each simulation, all these generators were scaled by the same factor). This way, the PV + wind generation fraction in the system ranges from $13 \%$ to $40 \%$ of total generation (curtailment excluded).

It is important to note that there are different possibilities in choosing the set of PV and wind generators when varying the amount of RE generation in the system. For example, tens of thousands potential wind and PV generators could be combined to reduce variability by employing geographic diversity [4]. Depending on particular goals (reducing carbon emissions, minimizing capital cost while achieving a certain level of RE, etc.), different sets of generators will be chosen. Without trying to exhaust all possibilities, in our present work we limit changes in the generation mix to concomitantly scaling wind and PV generators. Even with this restriction, the amount of $\mathrm{PV}+$ wind in the WECC regions ranges from $10 \%$ to $50 \%$ (Table I, CA No and RMPP, respectively) and PV / wind generation ratio varies from 3:1 to 1:20 (CA_So and NWPP). This diversity allows to probe into how PV and wind variability influence regional energy interchange.

\section{NET INTERCHANGE: THE EFFECT OF RENEWABLES}

The net interchange for the 6 US WECC regions differs by (i) total power transfer in or out of the region during the year and (ii) its variability. It is convenient to characterize the first by average (for the year) and the second by the standard deviation of the net interchange. Both values vary significantly

\footnotetext{
${ }^{2}$ http://www.energyexemplar.com, accessed on Nov 24, 2014. The Integrated Energy Model PLEXOS is used to simulate detailed economic unit commitment and dispatch and includes databases for existing and projected power generators, load distribution and renewable power [2]. This production cost model uses mixed-integer linear programming to minimize the cost of power production (including fuel, O\&M, startup costs) while meeting load and reserves requirements, transmission constraints, individual generators minimum time up/down constraints, etc. ${ }^{3}$ RMPP (Rocky Mountains Power Pool), CA_No(California North), Basin, CA_So (California South), AZNMNV (Arizona, New Mexico, Nevada), NWPP (North-West Power Pool)
}

from region to region and are affected by the amount of renewables.
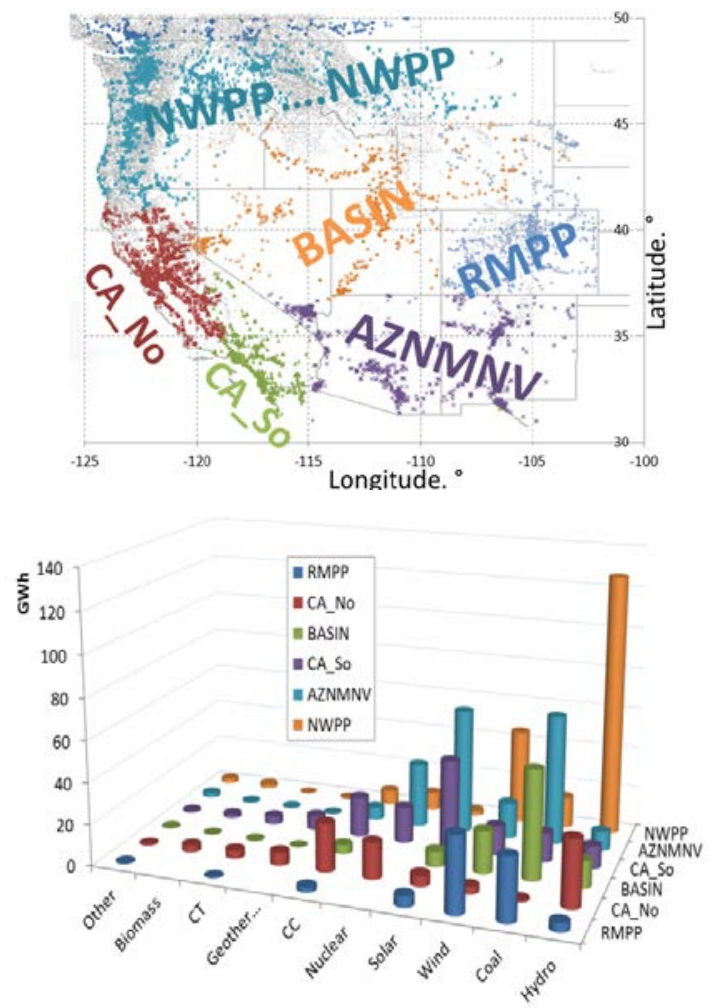

Figure 1. WECC regions (top, represented by color-coded bus locations) and generation mix (bottom) from PLEXOS input database and simulation results at $27 \%$ wind $+\mathrm{PV}$ generation fraction.

TABLE I. WECC GENERATION BY TYPE AND REGION (GWH BASED FRACTION, \% OF TOTAL). COLOR-CODED ARE VALUES THAT STAND OUT FROM COLUMN AVERAGE (RED - LARGER THAN AVERAGE, BLUE - SMALLER THAN WECC AVERAGE FOR THE GIVEN GENERATION TYPE).

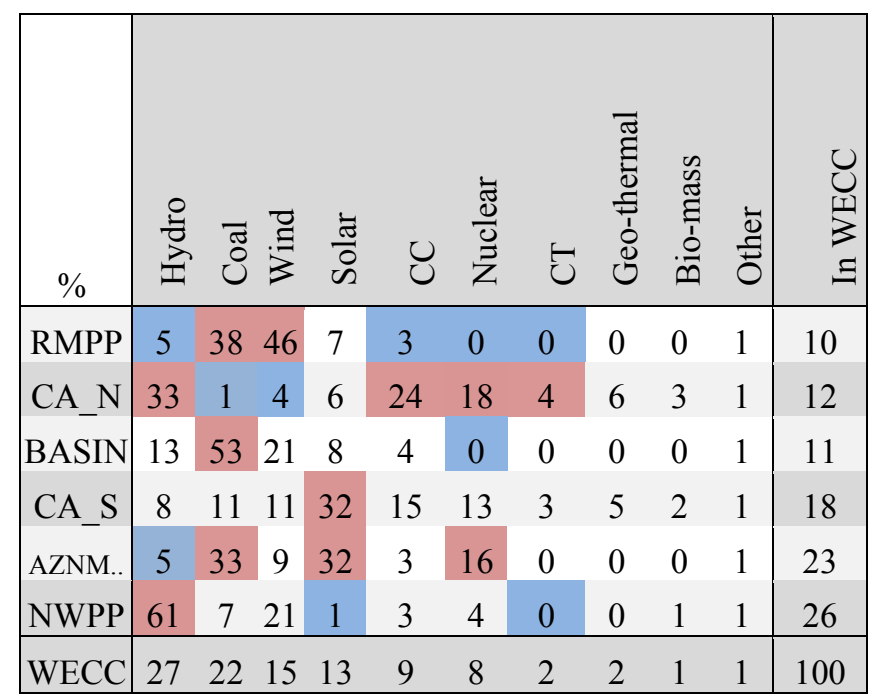


As seen in Figure 2, it is mostly the average interchange that is affected in both regions in California, while for AZNMNV and NWPP it is mostly the net interchange variability that responds to higher levels of PV and wind. ${ }^{4}$ The distribution of net interchange values widens with addition of renewables (Fig. 3, for the AZNMNV region).

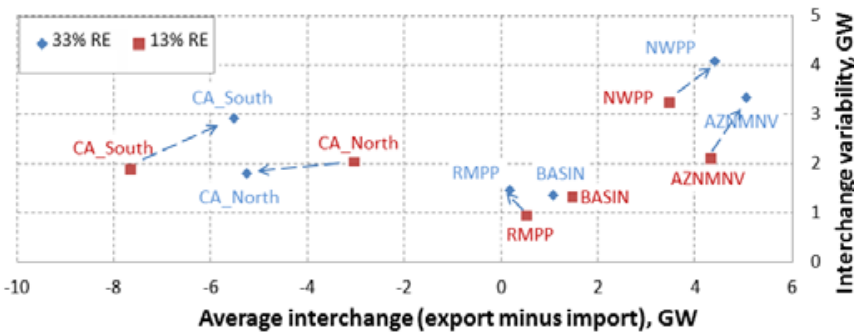

Figure 2. An example of the effect of renewables (PV and wind) on net interchange in WECC. The arrows show the effect of scaling up renewables.
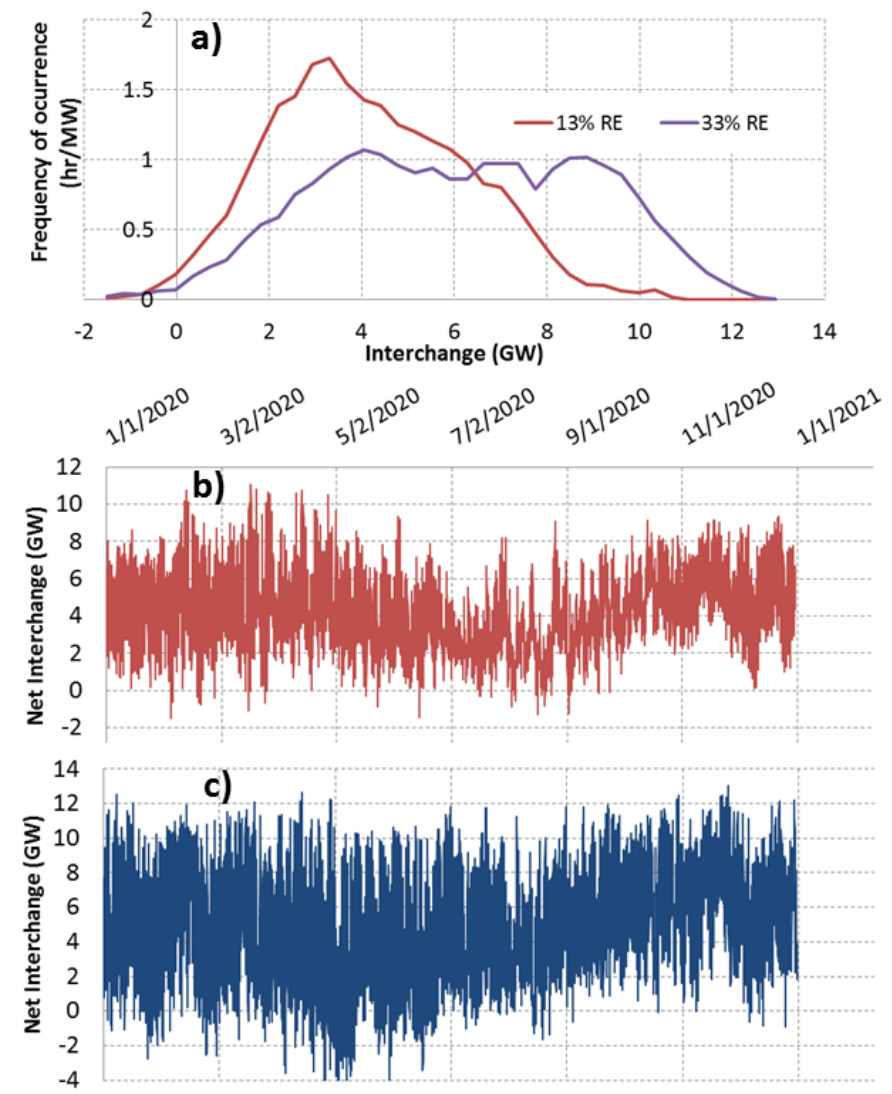

Figure 3. The effect of scaling up wind and PV on the net interchange for AZNMNV: the distribution (a) of net interchange values widens with addition of renewables in WECC from $13 \%$ to $33 \%$. Hourly net interchange time series are shown for the $13 \% \mathrm{RE}(\mathrm{b})$ and $33 \% \mathrm{RE}(\mathrm{c})$ cases.

\footnotetext{
${ }^{4}$ Note that net interchange $T$ is the geometric sum of its average $\langle T\rangle$ and standard deviation $\sigma_{T}:\left\langle T^{2}\right\rangle=\langle T\rangle^{2}+\sigma_{T}{ }^{2}$
}

To further quantify the effect of renewables, we define 'miscorrelation' between regional net load ${ }^{5}$ and the net load for the rest of WECC. It is reasonable to expect that the need for interchange is smaller between regions with highly correlated net loads. Conversely, poorly correlated net load would call for intense interchange. To quantify how poor are correlated the net loads, we use the 'mis-correlation':

$$
\operatorname{Mcorr}\{f, g\}=(1 / 2-1 / 2 \cdot \operatorname{Corr}\{f, g\})^{1 / 2}
$$

where $f(t)$ and $g(t)$ are two time-dependent quantities (in our case, the net load for a region and the net load for the rest of the system); $\operatorname{Corr}\{f, g\}$ is the correlation coefficient between $f$ and $g$, and $\operatorname{Mcorr}\{f, g\}$ is the 'mis-correlation'.

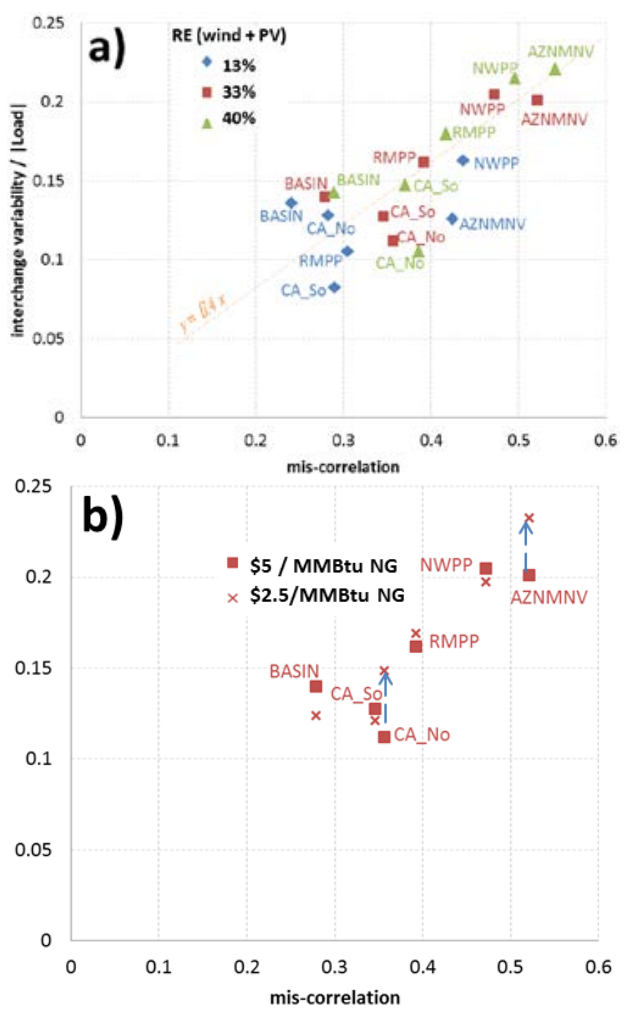

Figure 4. Net load 'mis-correlation' as the driver for inter-regional energy exchange variability: a) regional interchange variability tends to follow the net load 'mis-correlation' for various regions and at different levels of renewables; b) for the $33 \% \mathrm{RE}$ level, the interchange variability closer follows the net load 'mis-correlation' as the flexible natural gas (NG) generation begins to replace coal at lower NG fuel price.

Further, it is convenient to normalize the interchange variability (i.e. standard deviation) dividing it by the average regional load. Then (Figure 4a), the 'mis-correlation' of regional net load can be seen as the driving force and the

\footnotetext{
${ }^{5}$ Here, net load = load - PV - wind - hydro fixed dispatch.

${ }^{6}$ The correlation coefficient can be considered as $\cos (x)$, then
} the 'mis-correlation' is $\sin (x / 2)$. 
interchange variability as the direct response to it. This approach gives only an approximation for interchange variability, since it doesn't account for transmission limitations nor for wide differences in regional generation mixes (Table 1). Remarkably, at lower natural gas prices and higher flexibility in the system, the net interchange variability significantly closer follows the net load 'mis-correlation' (Figure 4b).

The 'mis-correlation' here quantifies the difference between regional and system-wide net load for a year. On shorter (weekly) time intervals, the difference between regional and system-wide net load also stands as the driving force behind regional interchange (Fig. 5). We consider the regional net load deviation from the weekly average $V^{A}{ }_{t}$, divided by the net load standard deviation. This regional quantity, subtracted by the similar quantity for the rest of the WECC, is the ordinate (the $\mathrm{X}$-axis) on the figure:

$$
X_{t}=V^{A}{ }_{t} / \sigma\left(N L^{A}\right)-V_{t}^{W E C C-A} / \sigma\left(N L^{W E C C-A}\right)
$$

Here, $N L^{A}{ }_{t}$ and $N L^{W E C C-A}{ }_{t}$ represent the net load at hour $t$ for the region $\mathrm{A}$ and for the rest of the $\mathrm{WECC}$, respectively ${ }^{7}$; $\sigma\left(N L^{A}\right)$ is the net load standard deviation; $X_{t}$ is the time-series analogue to the 'mis-correlation' between $N L^{A}{ }_{t}$ and $N L^{\text {WECC-A }}{ }_{t}$; $V^{A}{ }_{t}$ is the difference between $N L^{A}{ }_{t}$ and its weekly average.

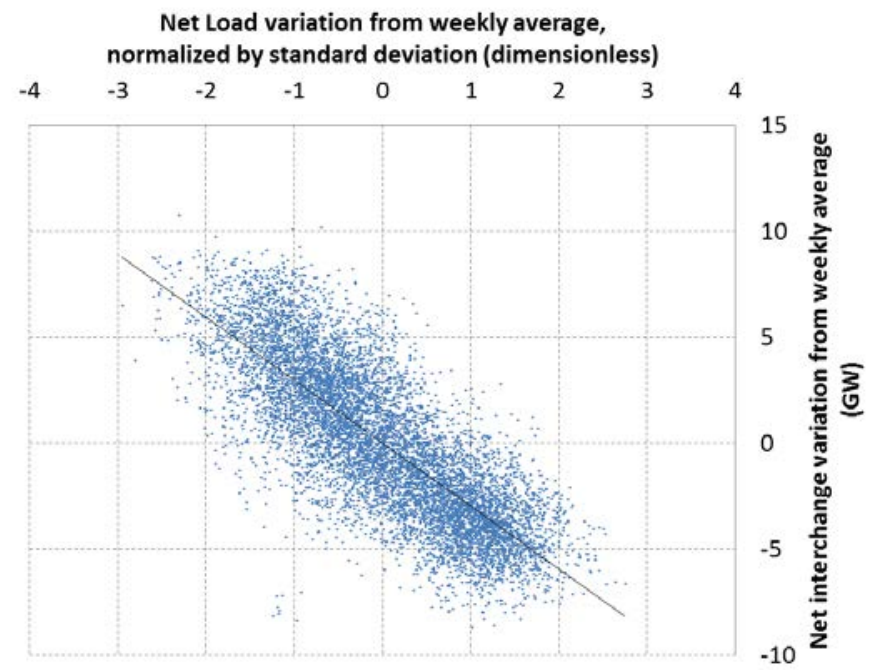

Figure 5. AZNMNV time-series: variations of regional net load from the weekly average correlate with regional interchange. The $33 \%$ wind + PV case is shown.

\section{CONCLUDING REMARKS}

Regional energy interchange variability is analyzed for the Western U.S. using a production cost model with varying levels of PV and wind generation in the system. The 'mis- correlation' in the net load is identified as the driving force behind regional net interchange variability.

Quantifying the driving force behind interregional energy exchange variability can be beneficial in several instances. It could provide an approximation for the interchange between regions without detailed modeling just by examining regional net loads. Clearly, this can only be an approximation (it doesn't account for actual transmission limitations or for differences in regional generation pools), but the range of scenarios it may apply to (with infinite combinations of solar/wind generation in the regions) seems to be a rational trade-off. When studying a region that is a part of a larger system, our approach could give a reasonable approximation to otherwise vaguely defined timevariable interchanges.

\section{REFERENCES}

[1] Mai, T.; Hand, M. M.; Baldwin, S. F.; Wiser, R. H.; Brinkman, G. L.; Denholm, P.; Arent, D. J.; Porro, G.; Sandor, D.; Hostick, D. J.; Milligan, M.; DeMeo, E. A.; Bazilian, M. (2014). Renewable Electricity Futures for the United States. IEEE Transactions on Sustainable Energy. Vol. 5(2), April 2014; pp. 372-378; NREL Report No. JA-6A20-58804. http://dx.doi.org/10.1109/TSTE.2013.2290472

[2] Lew, D.; Brinkman, G.; Ibanez, E.; Florita, A.; Heaney, M.; Hodge, B.M.; Hummon, M. ; Stark, G.; King, J.; Lefton, S.A.; Kumar, N.; Agan, D.; Jordan, G.; Venkataraman, S. The Western Wind and Solar Integration Study Phase 2.Technical Report NREL/TP-5500-55588, September 2013

[3] Ferryman, T.; Haglin, D.; Vlachopoulou, M.; Jian Yin; Net interchange schedule forecasting of electric power exchange for RTO/ISOs. Power and Energy Society General Meeting, 2012 IEEE.

[4] Short, W.; Diakov, V. (2013). Matching Western US Electricity Consumption with Wind and Solar Resources. Wind Energy. Vol. 16(4), May 2013; pp. 491-500.

\section{${ }^{7} \mathrm{~A}=\mathrm{AZNNMNV}$ for Fig. 5}

